\title{
Reactivation of NMDA Receptors by Synaptic Reentry Reinforcement, a Probable Cause of Auditory Hallucination in Schizophrenia
}

Shahriar Gharibzadeh ${ }^{*}$, Asma Darvishi and Maryam Darvishi

Associate Professor, Neuromuscular Systems Lab., Department of Biomedical Engineering, Amirkabir University of Technology, Tehran, Iran

*Corresponding author: Shahriar Gharibzadeh, Associate Professor, Neuromuscular Systems Lab, Department of Biomedical Engineering, Amirkabir University of Technology, Tehran, Iran, Tel: 2378-6454; E-mail: gharibza@yahoo.com

Rec date: Feb 7, 2014, Acc date: Apr 5, 2014, Pub date: Apr 10, 2014

Citation: Gharibzadeh S, Darvishi A, Darvishi M (2014) Reactivation of NMDA Receptors by Synaptic Reentry Reinforcement, a Probable Cause of Auditory Hallucination in Schizophrenia. Brain Disord Ther 3: 118. doi:10.4172/2168-975X.1000118

Copyright: ( 2014 Shahriar Gharibzadeh, et al. This is an open-access article distributed under the terms of the Creative Commons Attribution License, which permits unrestricted use, distribution, and reproduction in any medium, provided the original author and source are credited.

\section{Letter to Editor}

One of the positive symptoms of schizophrenia is auditory hallucination [1]. Studies suggest that frontal and temporal lobes are involved in this disturbance [2]. Another research demonstrates that in schizophrenic patient the level of NMDA (N-methyl-D-aspartate) receptor subunits such as NR2D increases in the prefrontal cortex [3], which may lead to abnormal receptor activation which can cause irregular situations such as delusions and hallucinations [3,4].

On the other hand, "reentry circuits", i.e. neuronal circular pathways which recycle electrical impulses to cause positive feedback, have been used to demonstrate some functional aspects of heart or mind. For example, it has been mentioned that reentry circuits are responsible for some cardiac arrhythmias. A study shows that for strengthening memory, it is needed to reactivate NMDA receptors in the CA1 of hippocampus during first weeks after learning and it is supposed that "repeated post-learning reinforcement of synaptic modifications, termed synaptic reentry reinforcement (SRR)" is necessary for storage of information in the long-term memory [4].
Based on abovementioned points, we hypothesize that reactivation of NMDA receptors by SRR in temporal lobe of schizophrenic patients may be one of the involving factors which produced auditory hallucinations. Surely experimental studies are needed to validate this hypothesis.

\section{References}

1. Kreinin A (2013) "Hearing voices" in schizophrenia: who's voices are they? Med Hypotheses 80: 352-356.

2. Hugdahl K (2009) "Hearing voices": auditory hallucinations as failure of top-down control of bottom-up perceptual processes. Scand J Psychol 50: 553-560.

3. Akbarian S, Sucher NJ, Bradley D, Tafazzoli A, Trinh D, et al. (1996) Selective alterations in gene expression for NMDA receptor subunits in prefrontal cortex of schizophrenics. J Neurosci 16: 19-30.

4. Wittenberg GM, Sullivan MR, Tsien JZ (2002) Synaptic reentry reinforcement based network model for long-term memory consolidation. Hippocampus 12: 637-647. 